\title{
Algunos "mitos" sobre España en la narrativa histórica del exilio alemán. Dos novelas de Lion Feuchtwanger
}

\begin{abstract}
This paper deals with the image of Spain and how it is misrepresented in the German historical narratives written during the exile period. This misrepresentation is due on the one hand to the writers' lack of knowledge of the historical context in which their works were set and on the other hand to the individual motivation of the authors themselves. Through an examination of the two novels which Lion Feuchtwanger set in Spain, Die Jüdin von Toledo and Goya, this article will try to analyse how in both cases the Spanish context offered the author the perfect frame to build the plot and the scenes and relate it to the historical moment Germany was experiencing. Furthermore, literary images and motifs will also be taken into consideration in order to prove how the reality of Spain in two very particular moments of its history was distorted in both novels.
\end{abstract}

Keywords: Exile literature; Historical Novel; Image of Spain; Feuchtwanger.

Zusammenfassung: Die vorliegende Arbeit versucht herauszuarbeiten, wie das Spanienbild im deutschen historischen Exilroman in vielfacher Hinsicht verfälscht worden ist. Dies ist einerseits bedingt durch die mangelnde Vertrautheit der Autoren mit dem Kontext, in dem ihre Romane spielen, andererseits durch die spezifischen Interessen, von denen sie geleitet sind, um

La autora es Profesora de la Universidad Complutense de Madrid. 
Stoff und Handlung zu konstruieren. Anhand der beiden Romane mit spanischen Themen von Lion Feuchtwanger, Die Jüdin von Toledo und Goya, werden die Anknüpfungspunkte analysiert, die der Rahmen der Iberischen Halbinsel dem Autor bot, um die Szenarien beider Romane im Zusammenhang mit der historischen Situation Deutschlands zu konstruieren, sowie die Motive und Bilder, die in beiden Romanen ein unzutreffendes Bild der spanischen Wirklichkeit in zwei wichtigen Perioden seiner Geschichte entstehen lassen.

Stichwörter: Exilliteratur; historischer Roman; Spanienbild; Feuchtwanger.

Resumen: El presente trabajo trata de poner de manifiesto cómo la imagen de España que se presenta en la narrativa histórica en lengua alemana durante el periodo del exilio está falseada en muchos aspectos debido, por un lado, al desconocimiento de los autores del contexto en el que insertan sus obras, así como a los propios intereses de los autores en sí a la hora de elaborar la trama. A través de las dos novelas de tema español de Lion Feuchtwanger, Die Jüdin von Toledo y Goya, se analiza el interés específico que el marco de la península ibérica ofrecía al autor para construir los escenarios de ambas obras en relación con el momento histórico que estaba viviendo Alemania, así como los motivos e imágenes que, en ambas novelas, falsean la realidad española de dos periodos muy singulares de su historia.

Palavras-chave: Literatura del exilio; novela histórica; imagen de España; Feuchtwanger.

"Die Spanier sind ohne Witz; sie halten den Kopf steif, wie sie ihren Kragen bügeln, und können nicht sehen, was auf der Erde los ist". Estas palabras de Heinrich Mann, extraídas de su novela Die Vollendung des Königs Henri Quatre recogen con enorme precisión la imagen con la que los españoles han entrado en la literatura alemana como individuos curiosos, inmersos en un entorno pintoresco y folclorista, en el que imperan unas formas de vida y unas costumbres únicas en el mundo, enormemente lejanas desde todo punto de vista a las de los ordenados y rigurosos países centroeuropeos,

1 Mann, Heinrich, Die Jugend des Königs Henri Quatre. Hamburgo 1964, 311-312. 
y habitado por unos individuos caracterizados, sobre todo, por cualidades tan singulares como ésta del orgullo que, sin ir más lejos, ha llegado a consagrarse como el paradigma del carácter español por excelencia en el ámbito cultural alemán. Que esto sea así no tendría mayor trascendencia si no fuera porque las obras de la literatura alemana que tienen España como escenario y a los españoles como protagonistas son preferentemente obras escritas por novelistas alemanes en el exilio ${ }^{2}$, los cuales no tenían en absoluto un conocimiento exhaustivo de la realidad histórica de España y que, precisamente por ello, se limitaron a transmitir una visión estereotipada y en muchos casos negativa de la realidad hispana. Para configurar esta imagen acorde exclusivamente con la finalidad perseguida en cada una de las obras en cuestión, los autores hicieron uso de los recursos propios de la novela histórica, género que, como es bien sabido, no tiene como meta una

2 No debe olvidarse que la novela histórica se convirtió en uno de los géneros preferidos por los autores en el exilio y que se generó un gran debate en torno a la problemática del género de la novela histórica. De hecho, el número de novelas históricas publicadas en esta época es una buena muestra del interés suscitado por el mismo, y llegó a tal extremo que los críticos vieron ya en ese momento la necesidad de separar las novelas de contenido trivial de aquellas de verdadero rigor literario: "Die Bücherproduktion der emigrierten Deutschen als Totalität - ein zum Himmel brüllender Skandal! [...] wenn das Belletristengezücht mit Büchern über Katharina von Rußland, Christine von Schweden, Josephine von Frankreich, über Ferdinand den Ersten, Philipp den Zweiten, Napoleon den Dritten, den falschen Nero und den echten Peter, mit dieser ganzen [...] Wissenschaft des Nichtwissenswerten dem Publikum Kleister ins Hirn schmiert und uns Verantwortungsschriftstellern, uns Denkmännern, uns Vorbereitern des Morgen die Luft nimmt, so trifft dies Pack von Gestrigen der saftigste Fluch! Fruchtet er nichts, dann macht nur weiter! Es gibt immer noch einige Isabellas, über die kein Roman vorliegt; und auch Ramses der Vierte, Pippin der Mittlere, Winrich von Kniprode, Sultan Suleiman, Melanie die Ausgefallene von Paphlagonien fanden bisher, soweit ich sehe, ihren Monographen nicht. [...] man kann doch nur in ein Gelächter ausbrechen über die Unverschämtheit von Buchmachern, in dieser Zeit mit Texten ernstgenommen werden zu wollen, in denen eine völlig gleichgültige oder überhaupt keine Frage gestellt wird". Hiller, Kurt, Profile. Prosa aus einem Jahrzehnt. Paris 1938, 236. Citado según Dietschreit, Frank, 89-90. 
reproducción exhaustiva de los acontecimientos de la Historia pasada, sino tan sólo una recreación ficticia que se lleva a cabo siempre según convenga al argumento de la narración que se trate. De ahí que no carezca de interés analizar con detalle el proceso de rescritura de los distintos momentos de la Historia de España llevado a cabo por estos autores para construir el trasfondo local de la acción que se desarrolla en estas novelas y que no es otro que el de diferentes épocas - curiosamente de singular importancia-, de la Historia de una nación caracterizada ya de entrada negativamente en todas ellas ${ }^{3}$.

De entre los numerosos autores que escribieron obras de tema español en el marco de este género durante el periodo del exilio y los años subsiguientes destaca, sin duda, la figura de Lion Feuchtwanger (18841958), no sólo por las obras en sí, sino también por el hecho de que su producción literaria estuvo siempre acompañada por reflexiones teóricas en las que el propio autor expuso sus ideas acerca de su quehacer literario, la práctica totalidad del cual ha de enmarcarse necesariamente dentro del género aquí tratado. Por otro lado, las dos novelas de tema español que compuso entre 1951 y 1954 recogen dos momentos importantes para la legitimación del poder en España: el nuevo impulso que Alfonso VIII dio a la Reconquista en aras de conseguir la unidad nacional, por un lado, y la dejadez con la que Carlos IV gobernó sobre los territorios que regentes anteriores habían conseguido para la nación, por otro. Feuchtwanger compuso, pues, dos novelas centradas en torno a la figura de un importante regente, a partir del cual pudo establecer su visión del poder y, con ella, plasmar de forma enormemente visual las consecuencias negativas que el mal uso del mismo trae consigo. Es, por tanto, el poder, y las

$3 \quad \mathrm{M}^{\mathrm{a}}$ Luisa EsTEVE analiza exhaustivamente todas estas obras en su estudio sobre la imagen de España en la narrativa alemana del exilio que recojo en la bibliografía. Menciono para el lector interesado los títulos de algunas obras a las que no voy a hacer alusión aquí, pero que resultan imprescindibles a la hora de tener una visión más amplia sobre la imagen de España y sus gobernantes en la literatura alemana: Hermann Kesten, Ferdinand und Isabella (1936); Hermann Kesten, König Philipp der Zweite (1938); Ernst Sommer, Botschaft aus Granada (1938); Valeriu Marcu, Die Vertreibung der Juden aus Spanien (1934); Ludwig Marcuse, Ignatius von Loyola (1935); Bruno Frank, Cervantes (1934). 
relaciones que en torno a él se establecen, el elemento alrededor del cual se aglutinan las dos novelas y que permite, en consecuencia, un análisis conjunto de ambas obras.

Por lo que respecta a la cuestión teórica, no deja de llamar la atención el hecho de que recurrir a este género que gozaba de tan negativo prestigio obligó a los mismos escritores a realizar una labor de justificación respecto del mismo de la que, de haberse tratado de otro género en boga, no hubieran precisado en absoluto. De ahí que el análisis del corpus de obras de este género resulte enormemente enriquecedor y valioso, no sólo por lo que a las obras en sí se refiere, sino también por todo el conjunto de textos teóricos que las acompañan y que permiten analizar a un mismo tiempo su expresión en la práctica. En mayor medida unos que otros, todos los autores se esforzaron por dejar claro que la novela histórica se adaptaba mejor que ningún otro género al objetivo perseguido por los escritores en el exilio, y así, siguiendo el modelo propuesto por Walter Scott, todos ellos trataron de defender la validez del género frente a los ataques de trivialidad, a los que había sido sometido por la crítica. En este sentido, por ejemplo, se manifestó también Alfred Döblin en uno de sus ensayos más conocidos, el titulado Der historische Roman und wir (1936), donde explica detalladamente el proceso creativo de la novela histórica como un proceso de tres fases en el que el autor encuentra a un personaje de la Historia, lo rescata del pasado en el que se ha mantenido estático y lo rescribe dando lugar a un proceso en movimiento, de adaptación al presente, que hace percibir al personaje en cuestión como real e identificarlo en muchos casos con algún personaje de la Historia presente ${ }^{4}$. Pues el objetivo de toda novela que se enmarque dentro de este género no es en absoluto el de presentar simplemente una serie de acontecimientos históricos que puedan resultar de interés al lector actual, sino proporcionarles un sentido que no tenían de por sí desde la perspectiva historiográfica y que adquieren en el momento de pasar al relato de carácter ficcional, todo ello, evidentemente, para cumplir la función de esconder tras el velo de la Historia la realidad del presente.

4 Cfr. Döвlin, Alfred, «Der historische Roman und wir», en DöBLIN, Alfred, Aufsätze zur Literatur. Walter: Olten 1963, 180 ss. 
Para Lion Feuchtwanger, tal vez el autor que más veces se cuestionara la validez de este tipo de escritura, el género de la novela histórica tenía una finalidad evidente, que se avenía además a la perfección con la temática que suele atraer con frecuencia a aquellos escritores que, como él, se vieron obligados a vivir una situación de exilio. En una conferencia publicada con el título Vom Sinn und Unsinn des historischen Romans y que el autor pronunció en 1935 en el Congreso Internacional de Escritores que tuvo lugar ese año en París, Feuchtwanger dijo lo siguiente:

Ich für mein Teil habe mich, seitdem ich schreibe, bemüht, historische Romane für die Vernunft zu schreiben, gegen Dummheit und Gewalt, gegen das, was Marx das Versinken in die Geschichtslosigkeit nennt. Vielleicht gibt es auf dem Gebiet der Literatur Waffen, die unmittelbarer wirken: aber mir liegt [...] am besten diese Waffe, der historische Roman, und ich beabsichtige, sie weiter zu gebrauchen. ${ }^{5}$

Esta opinión, que puede parecer un tanto unilateral, tiene su origen sin duda alguna en el hecho constatado de que el género de la novela histórica no era en absoluto un género bien visto en la época, pues había pasado a pertenecer al ámbito de la literatura trivial, debido a las connotaciones negativas que había ido acumulando a lo largo de los años, como el hecho de tener una trama demasiado cargada de aventuras, un trasfondo excesivamente colorista o un lenguaje claramente patético, entre otras. Feuchtwanger, no obstante, veía en el género la posibilidad de ir más allá y ofrecer al lector justamente lo que necesitaba en ese momento, de ahí que su interés fundamental girase en torno a dos cuestiones básicas, de las que no puede prescindirse siempre que se analizan las manifestaciones de este género: la relación entre una reproducción exacta y científica o ficticia y literaria de la Historia, y la justificación de un mensaje actual encubierto por la distancia en el tiempo que procuraba el pasado histórico. Respecto de la primera cuestión, Feuchtwanger estaba plenamente convencido de que una novela histórica resultaba mucho más viva, más ejemplar y más efectiva que una descripción exhaustiva de los acontecimientos históricos ${ }^{6}$. De ahí que su

5 Feuchtwanger, Lion, «Vom Sinn und Unsinn des historischen Romans», en FeuCHTWANGER, Lion, Ein Buch nur für meine Freunde. Fischer: Frankfurt 1984, 501. 
producción literaria, que se enmarca toda ella en el campo de este género literario, no pretenda en absoluto una representación real de la Historia, sino todo lo contrario, construir un mundo ficcional que despierte la ilusión del lector, lo cual resultará más beneficioso para el objetivo final que el autor persigue en todas sus novelas: ejemplificar la realidad del momento presente a través del pasado, utilizando el pasado y sacando de él todo el provecho que éste es capaz de ofrecer, pues los motivos que movieron una vez a los hombres en siglos anteriores son exactamente los mismos que mueven a los hombres de ahora ${ }^{7}$. Y es que, ciertamente, la narrativa histórica de Feuchtwanger podría definirse por una constante, que no es otra que la más absoluta y firme convicción por parte del autor en la repetición, en diversos momentos del fluir temporal, de los mismos acontecimientos, aunque con otros ropajes: la esencia del hombre permanece invariable con el curso del tiempo y, por ende, las fuerzas que mueven e impulsan a los pueblos han sido las mismas desde el principio de la Humanidad. Es por esto por lo que el autor afirma:

Was gewesen ist, das gleiche wird sein, und was geschehen ist, das gleiche wird geschehen, und es geschieht nichts Neues unter der Sonne. Und geschieht auch etwas, von dem man sagt: Siehe, das ist

Cfr. Feuchtwanger, Lion, op. cit., 499.

En este sentido, Feuchtwanger se considera heredero de la técnica literaria de Walter Scott, quien construía la Historia de manera que aparecía en sus textos en un constante fluir hacia el presente y hacia el futuro. No es de extrañar que Feuchtwanger considere por tanto a Scott como "el creador de la auténtica novela histórica de nuestra época" (Feuchtwanger, Lion, Das Haus der Desdemona oder Größe und Grenzen der historischen Dichtung. Fischer: Frankfurt 1986, 47). También Fritz Rudolf Fries, en un epílogo añadido a ediciones posteriores y también a la traducción española de Goya reflexiona sobre esta cuestión respecto de la novela histórica como género literario para Feuchtwanger: "Pero ¿qué es la Historia sino el testimonio de aquellos que han vivido antes que nosotros? Feuchtwanger, a lo largo de toda su vida, ha interpretado esta cuestión de diferentes formas. Y siempre enfocando al lector, ya que éste se veía forzado a una comparación: no debía contemplar el montón de ilustraciones del pasado sólo para su entretenimiento. Los paralelismos con el presente debían darle que pensar.” Fries, Fritz Rudolf, Epilogo, en Feuchtwanger, Lion, Goya. Edaf: Madrid 1994, 557 [Traducción de Ana Tortajada]. 
neu, ist's doch zuvor auch geschehen in den Zeiten, die vor uns gewesen sind. ${ }^{8}$

La esencia del hombre permanece, pues, inalterable al paso del tiempo, y en este mismo sentido, todo aquello que motiva a un pueblo en su conjunto sigue permaneciendo también inalterable en el devenir de la Historia, de ahí que pueda utilizarse el pasado como recurso para interpretar el presente, al crear con ello una distancia que produce en el lector un efecto inesperado, pues, en lugar de entender el pasado le ayuda a entender el presente distanciándolo de él. Por otro lado, el género de la novela histórica se adapta a la perfección para relatar hechos de carácter político, interrelacionados en mayor o menor medida con hechos privados en el entramado de una historia ficticia. La presentación de los acontecimientos suele realizarse a través de un proceso más o menos condicionado a esta generalidad, de lo cual resulta un conjunto de carácter histórico en el que lo público y lo privado, lo social y lo individual, lo constante y lo cambiante, comparten un mismo escenario, por lo que, en definitiva, lo histórico, lo ahistórico y lo ficticio en conjunto dan lugar a un entramado en el que la Historia adquiere una posición concreta que no es otra que la que decide el propio autor. El hecho histórico que se narra no procede, por tanto, de la Historia en sí, tal como aparece narrada por los historiadores, sino de un vacío en la vida privada y pública de un personaje histórico concreto que el escritor llena a través de su narración ${ }^{9}$. Siendo esto así, la finalidad perseguida por los autores alemanes en el exilio no podría lograrse mejor con ningún otro género literario, dado que, efectivamente, la acción que recogen en sus obras no es sino un episodio de la vida de un personaje famoso que nunca se hallará en los libros de Historia, y que el autor puede modelar a voluntad dentro del marco, absolutamente inmodelable, de la Historia.

Resulta interesante observar que la Historia de España ha sido de interés para los autores alemanes a lo largo de diferentes épocas de la historia

Feuchtwanger, Lion, Der falsche Nero. Aufbau: Berlín 1980.

A menudo ocurre también que el protagonista puede ser un personaje ficticio cuya existencia se apoya en otros personajes secundarios, estos sí históricos, como es el caso de Jehuda en Die Jüdin von Toledo. 
de la literatura. De dónde surge este interés se deba quizá a la curiosidad o a la atracción hacia el pueblo español y su cultura, así como hacia elementos singulares del carácter español completamente ajenos y diametralmente opuestos, si se quiere, al alemán: el espíritu belicoso, el acendrado individualismo, la genialidad quijotesca, el hidalguismo, la arrogancia... ${ }^{10}$ Es precisamente a partir de estos elementos singulares y no del trasfondo mucho más amplio de la Historia de donde los escritores alemanes partirán para su reconstrucción del entramado histórico que les ha de servir de escenario para sus novelas, pero que, en definitiva, es mucho menos importante que lo que los propios personajes aportan de por sí. Es decir, que la reconstrucción histórica que se lleva a cabo en las obras de los narradores del exilio alemán tiene lugar a partir de los personajes retratados en ellas y no de los acontecimientos históricos, dando lugar así a una visión de las distintas épocas de la Historia de España definida única y exclusivamente por las características propias de los individuos que desempeñan un papel en las novelas y que se convierten de ese modo en portadores de las características definitorias de toda una nación y, por ende, del devenir histórico de la misma. Es, pues, un proceso de rescritura de la Historia que tiene lugar a través de la presentación de los personajes, de los individuos, de los "españoles", de las características de ese pueblo tan singular y diferente a la vez. Y así, partiendo de la descripción individual, los narradores reconstruyen

10 Cfr. en este sentido el ensayo de Ramón Menéndez Pidal, Los españoles en la Historia, 73-145, en el que se retratan con precisión meridiana las características que definen al pueblo español y que, curiosamente, no aparecen en las obras mencionadas de los autores alemanes a excepción, eso sí, de la del famoso orgullo, malentendido, evidentemente, y no aplicado en la medida que corresponde a la idiosincrasia del pueblo español. Menéndez Pidal destaca por encima de cualquier otra la sobriedad como cualidad básica del carácter español; única y exclusivamente sobre esta cualidad han de entenderse las demás, no de forma aislada, sino en relación constante con ella. El desinterés, la idealidad, la religiosidad o el individualismo, no se comprenden de otra forma más que partiendo de la sobriedad como característica base que da origen a todas las demás, de ahí que tanto Feuchtwanger como el resto de los autores cometan el error de advertir en el pueblo español una única cualidad y exagerarla, sin conocer siquiera cuál es su origen. 
el gran retablo de la vida y la sociedad española de diferentes épocas en sus más destacados y relevantes aspectos: las condiciones de vida en el campo, en las ciudades, las costumbres de los habitantes, la esencia de lo popular, la política, la Iglesia, la salud pública y muchos más.

Las obras de Lion Feuchtwanger que tienen España como escenario abarcan un periodo muy amplio de la Historia española: desde el siglo XII, en que España está en pleno proceso de unidad nacional, hasta comienzos del XIX, en que, por el contrario, el país ha comenzado ya a perder los territorios que antaño formaran aquel imperio en el que nunca se ponía el sol. Se trata de las novelas Die Jüdin von Toledo (1955) y Goya oder Der arge Weg der Erkenntnis (1951). Ambas, con el rey Alfonso VIII de Castilla y el borbón Carlos IV como portadores del poder, conforman en su conjunto dos momentos de la monarquía española enormemente significativos si se atiende a la circunstancia común que ha dominado desde siempre la Historia del país: la consecución de una unidad nacional. En las dos aparece, si no como personaje protagonista, desde luego sí ocupando un papel de enorme importancia la figura del gobernante presentada por el autor desde un punto de vista siempre negativo: el espíritu de poder -ya esté representado en el afán guerrero, en la conquista o en el desinterés- es un espíritu que el autor pretende estigmatizar de manera radical por los efectos perniciosos que la propia Historia ha demostrado que lleva consigo. Ésta y no otra es la finalidad que persigue Feuchtwanger en la totalidad de sus novelas, y ¿qué mejor escenario para ello que la distancia en el tiempo y en el espacio que proporcionan diversos momentos de la Historia de un país siempre tan desconocido, a la vez que atractivo, para el mundo de habla alemana?

El contexto histórico en el que se enmarca Die Jüdin von Toledo $(1955)^{11}$, presentaba para el autor una similitud muy grande con los acontecimientos acaecidos en Alemania durante el periodo anterior a la II Guerra Mundial, de manera que no resulta extraño que Feuchtwanger utilizara este periodo de la Historia española, tan atractiva y sugerente para los alemanes por los rasgos exóticos de los que siempre se la ha

11 En realidad, la novela se editó un año antes, en 1954, con el título de Spanische Ballade, pero Feuchtwanger cambió el título en la edición de 1955 y éste es el que se ha conservado a partir de entonces. 
dotado, para escribir una de sus novelas más emblemáticas. La España del siglo XII, en pleno auge de la Reconquista, es para el autor un impresionante escenario de luchas entre cristianos y musulmanes, de cruzadas y persecuciones de judíos, pues para los españoles la guerra tiene un valor sagrado en el que creen ciegamente, y así, el ideal guerrero aparece representado en sumo grado en la figura del monarca Alfonso VIII. Son muchas las páginas que el autor dedica a describir la furia guerrera del monarca: la guerra es para él mandato de Dios y la fama del buen guerrero es el único bien supremo que todo hombre debe estar dispuesto a alcanzar, pues sólo en la guerra se puede demostrar lo que vale un hombre, lo que vale un pueblo. Además, el rey está obligado a ello, ya que en la España de la Reconquista, el monarca era investido por Dios con la potestad real para hacer conquistas y ampliar sus dominios librando las tierras de infieles. Alfonso se siente, por tanto, como un guerrero enviado por Dios para conseguir reinar en toda España, imponiendo la religión cristiana en todas las tierras conquistadas y librando a la península de la perniciosa influencia de los herejes ${ }^{12}$. De lo que se trata, en definitiva, es de hacer realidad una idea que ha impulsado desde siempre la Historia española, es decir, de progresar en el camino hacia una unidad nacional, perseguida desde antaño. Y es que, con los ojos cerrados ante las demandas laicas y secularizadoras de los ámbitos progresistas, el poder se aferró a la idea de alcanzar la definitiva nación católica, esto es, una nación en la

12 La belicosidad de Alfonso, que tanto insiste el autor en describir, ha de entenderse como recurso para la recreación del entorno histórico; es el tipo del guerrero medieval que cree en la misión sagrada de las cruzadas y que no encuentra la paz más que, terrible contradicción, en la guerra: "Don Alfonso mußte nicht, wie er gefürchtet hatte, die Festung Alarcos hergeben, die liebe Stadt, die er in seinem ersten Feldzug dem Feinde abgewonnen und seinem Reiche zugefügt hatte, und auch die Kriegsentschädigung war nicht übermäßig hoch angesetzt. Aber acht Jahre Waffenstillstand! Der junge, ungestüme König, Soldat durch und durch, sah nicht, wie er die Geduld aufbringen sollte, die Ungläubigen sich acht endlos lange Jahre ihres Sieges brüsten zu lassen. [...] Er war Soldat und nicht Rechner, Soldat und immer wieder Soldat. Und das war gut in einer Zeit, da Gott den Fürsten der Christenheit unermüdlichen Kampf gegen die Ungläubigen auferlegt hatte". Feuchtwanger, Lion, Die Jüdin von Toledo. Frankfurt: Fischer 1990, 19-21. 
que la sociedad estuviera integrada en el Estado, la religión definiese de forma clara y contunden la idea de nación unida, y la política sólo tuviera como misión la defensa a ultranza de esta idea y facilitar la comunicación entre la Iglesia y el pueblo. Feuchtwanger no sabe ver esta idea que subyace tras toda una política que podría tacharse de expansionista, pues el autor tan sólo insiste en la idea de que España es una nación forjada por y para la guerra. Es precisamente en este sentido en el que el autor presenta al monarca castellano como el prototipo del gobernante español, pues para él la imagen del caballero cristiano no se ha borrado todavía ${ }^{13}$. De ahí que este elemento tan importante en la constitución de lo que siglos después sería España quede empañado aquí por una visión del guerrero enfrentado al hombre de paz, representado en este caso por un judío, en aras de la finalidad perseguida al dar forma literaria a un acontecimiento de la biografía del rey, en el cual parece pesar más lo legendario que lo real: su amancebamiento con la bella judía Raquel. Y es que, ciertamente, el trasfondo histórico en que se desarrolla la historia de Raquel y Alfonso debió ejercer sobre él una influencia mayor que muchos otros, pues el marco histórico y los escenarios en que se inserta la acción de la novela tienen en ella una importancia mucho mayor que en obras anteriores. El autor describe con sumo detalle la España del siglo XII, con sus cruzadas, las luchas entre cristianos y musulmanes en la península y la precaria situación de la población judía que ya empezaba a ser perseguida en el norte de Europa. La acción se sitúa en los años inmediatamente anteriores y posteriores a la batalla de Alarcos (1195), en los años del paso de la sociedad feudal a la burguesa, o lo que es lo mismo, en una época en la que conviven el entusiasmo feudal por la guerra y el deseo de aventuras frente a la razón y los deseos de paz de los ciudadanos, el espíritu de cruzada y el fanatismo religiosos frente a la tolerancia y la aceptación de la convivencia de las tres religiones. Algo, por otro lado, muy típico de la narrativa de Feuchtwanger, caracterizada siempre por los contrastes excesivamente marcados, por las antítesis radicales: amor y odio,

13 En cierto sentido es posible que Feuchtwanger no exagere en este punto, pues es sabido que Cervantes, muchos siglos después, no hizo otra cosa con su Don Quijote que intentar ridiculizar a través de él el ideal caballeresco, aún presente en la sociedad. 
lealtad y traición, razón y fanatismo, guerra y paz. Estos contrastes están personificados en la novela en los dos grupos de personajes antitéticos en torno a los cuales se definen las relaciones de poder a lo largo de toda ella: los que sólo entienden el poder legitimado por la guerra (Alfonso, Rodrigue y Garcerán), y los que sólo lo entienden con la paz (Jehuda, Musa y Benjamín). Que la Iglesia católica desempeña un papel fundamental en todo este entramado es algo que no escapa a la percepción del lector. Sus relaciones de poder con el Estado se irán fotaleciendo hasta extremos tales que Feuchtwanger sabe muy bien expresar en su novela sobre Goya, donde el peso de la Santa Inquisición está por encima del propio poder real. Lo que aquí se anuncia, allí se hace realidad.

Visto así, podría parecer excesivo el rigor con el que el autor se detiene en la descripción de un carácter que poco tiene que ver con el pacifismo que se desprende del conjunto de su producción literaria. Pero la técnica que utiliza Feuchtwanger es, efectivamente, la del contraste, y para que éste resulte más efectivo, la descripción del monarca enardecido por el furor guerrero ha de ser tanto más detallada precisamente para hacer resaltar con ello los valores del que es el verdadero protagonista de la novela, Jehuda, el padre de Raquel, por medio del cual restará valor al ideario guerrero de Alfonso. Es, como dice $\mathrm{M}^{\mathrm{a}}$ Luisa Esteve, "una alternativa a la historia"14 lo que Feuchtwanger ofrece aquí al lector, haciendo de Jehuda el representante y la personificación de una idea bien diferente de poder: el poder de la sabiduría que ha de fomentar la coexistencia pacífica de todos los ciudadanos. Esta política de paz y progreso, basada en el florecimiento económico, existió en la España medieval y a ella dieron pie efectivamente los judíos; es, por tanto, este concepto de alternativa ofrecida para la Historia lo que interesa realmente al autor, dado que Jehuda aparece como el prototipo del gobernante ideal, pues es él quien, a lo largo de toda la obra, no ceja en su

14 Cfr. Esteve Montenegro, 35: "Éste es el ideal que después de todas las amargas y sangrientas experiencias de la segunda guerra mundial, ha venido dominando la actuación de los políticos. Feuchtwanger, impregnado igualmente de esta idea, quiere hacérnosla ostensible trasladada a una época y un ambiente en que apenas se cree concebible: la España del siglo XII". He aquí cómo el autor se sirve del mencionado efecto de distancia histórica. 
empeño de hacer ver al monarca las posibilidades de desarrollo de su reino si se vive en paz, mostrándole las innumerables riquezas que se pueden extraer de los fértiles campos, de los ríos o de las entrañas de la tierra ${ }^{15}$. Con esta idea de convivencia pacífica precisamente se inicia la novela, en una de las descripciones más logradas de toda la obra:

Die neuen Herren [die Moslems] brachten mit sich eine überlegene Kultur und machten das Land zu dem schönsten, bestgeordneten, volkreichsten Europas. Von kundigen Architekten und einer weisen Baupolizei geplant, entstanden große, herrliche Städte, wie sie der Erdteil seit den Römern nicht mehr gekannt hatte. [...] Die Moslems brachten die vernachlässigte Landwirtschaft wieder hoch und gewannen dem Boden durch kluge Bewässerung ungeahnte Fruchtbarkeit ab. Sie förderten den Bergbau durch eine neue, hochentwickelte Technik. Ihre Weber stellten kostbare Teppiche her und erlesene Tuche, ihre Zimmerleute und Bildhauer delicate Holzkunst, ihre Kürschner jede Art Pelzwerk. Ihre Schmiede schufen Gegenstände höchster Vollendung für friedliche wie für kriegerische Zwecke. [...] Künste und Wissenschaften blühten wie bisher niemals unter diesem Himmel. Erhabenes und Zierliches mischte sich, die Häuser auf besondere, bedeutende Art zu schmücken. [...] Den Unterworfenen zeigten die Moslems Milde. Für ihre Christen übertrugen sie das Evangelium ins Arabische. Den zahlreichen Juden, die von den christlichen Westgoten unter strenges Ausnahmerecht gestellt worden waren, räumten sie bürgerliche Gleichheit ein. Ja, es führten unter der Herrschaft des Islams die Juden in Spanien ein so glückhaft erfülltes Leben wie niemals vorher seit dem Untergange ihres eigenen Reiches. [...] Länger als drei Jahrhunderte dauerte dieses Blühen. ${ }^{16}$

A través de la presentación de esta visión histórica de la realidad medieval, Feuchtwanger quiere hacer llegar a sus lectores dos mensajes fundamentales: en primer lugar, el de la eterna repetición de los acontecimientos históricos plasmada a través de las persecuciones a que se ha visto sometido el pueblo

\footnotetext{
15 Cfr. Esteve Montenegro, 35 ss.

16 Feuchtwanger, Lion, Die Jüdin von Toledo, 9-10 .
} 
judío y, en segundo, el de que es posible crear una sociedad en la que individuos de distintos credos puedan convivir pacíficamente si se deja a un lado el espíritu belicoso dominante. Con ello, el autor consigue los dos propósitos antes mencionados que han de estar en la base de toda composición que se enmarque dentro del género de la novela histórica, a la vez que una rápida identificación del lector con acontecimientos muy similares que él mismo ha vivido en su propia piel. De este modo, el proceso de reconocimiento al que Feuchtwanger somete a sus lectores se convierte en un proceso dialéctico en el que el presente se reconoce a partir del pasado.

No menos contundente que esta descripción inicial es la que el autor utiliza para introducir al lector en la España de Francisco de Goya:

Gegen Ende des achtzehnten Jahrhunderts war fast überall in Westeuropa das Mittelalter ausgetilgt. Auf der iberischen Halbinsel, die auf drei Seiten vom Meer, auf der vierten von Bergen abgeschlossen ist, dauerte es fort.

Um die Araber von der Halbinsel zu verdrängen, hatten vor Jahrhunderten Königtum und Kirche ein unlösliches Bündnis eingehen müssen. Der Sieg war möglich nur, wenn es den Königen und den Priestern gelang, die Völker Spaniens durch strengste Disziplin zusammenzuschweißen. Es war ihnen gelungen. Sie hatten sie vereinigt in einem inbrünstig wilden Glauben an Thron und Altar. Und diese Härte, diese Einheit war geblieben. [...] Die Spanier hatten über Don Quichotte gelacht, aber ihren Willen zur Tradition nicht aufgegeben. Länger als sonstwo in Westeuropa hielt sich auf der Halbinsel das mittelalterliche Rittertum. Kriegerische Tugend, bis zur Tollheit heldisches Gehabe, hemmungsloser Frauendienst, herrührend aus der Verehrung der Jungfrau Maria, diese Eigenschaften blieben die Ideale Spaniens. Die ritterlichen Übungen, längst ohne Sinn, hörten nicht auf.

Verknüpft mit diesem kriegerischen Gewese war eine leise Verachtung der Gelehrsamkeit und des Verstandes. Desgleichen ein ungeheurer Stolz, berühmt und berüchtigt über die Welt, Stolz der Gesamtheit auf die Nation, Stolz des einzelnen auf seine Kaste. Das Christentum selber verlor in Spanien seine Demut und seine Heiterkeit, es nahm ein wildes, düsteres, herrisches Gepräge an. Die Kirche wurde hochfahrend, kriegerisch, männlich, grausam. 
So war noch um die Wende des achtzehnten Jahrhunderts das Land das altertümlichste des Erdteils. Seine Städte, seine Trachten, die Bewegungen seiner Menschen, ja ihre Gesichter muteten den Fremden seltsam starr an, Überbleibsel der Vorzeit. ${ }^{17}$

Basándose también en la idea de la pervivencia del ideal caballeresco y guerrero de la Edad Media, Feuchtwanger describe una España dominada aún por las ideas medievales, en la que el poder terrenal y el poder religioso formaban desde hacía siglos una alianza imposible de disolver, forjada precisamente a lo largo de los muchos siglos de lucha contra el infiel. De esta forma, cuando el resto de las naciones europeas habían superado ya con creces estos ideales anclados en el pasado, España, ahora ya unida, seguía idealizando las virtudes guerreras y el espíritu cortesano hasta tal punto que las prácticas caballerescas, carentes ya de sentido, seguían aún en vigor. Pero lo más negativo del momento es que este talante belicoso, que el lector ha de entender como rasgo específico del pueblo español, llevaba consigo un manifiesto desprecio por la cultura y la razón y, como compensación por ello, un enorme orgullo nacional nacido, cosa que el autor no menciona, no de la arrogancia caballeresca, sino de la sobriedad y la austeridad castellanas, algo demostrable incluso en el carácter sombrío e inflexible de la Iglesia católica, que durante esos años cobró en España formas estrictamente rigurosas y negativas que la convirtieron en un símbolo claro del terror más que del recogimiento y la devoción religiosas. Con una visión así no extraña que España fuera para Feuchtwanger el país más arcaico de Europa a comienzos del siglo XIX. Y es cierto que en este sentido tal vez sí lo era.

Es más, Feuchtwanger tiene incluso mucha razón cuando advierte serias diferencias entre España y el resto de Europa; en lo que no se detiene el autor es en el análisis del porqué de estas enormes diferencias, fruto todas ellas en realidad de una conciencia nacional muy distinta a la de otras naciones y del proceso a lo largo del cual se había ido gestando esta conciencia, así como de unos rasgos propios del carácter hispano difíciles

17 Feuchtwanger, Lion, Goya oder Der arge Weg der Erkenntnis. Frankfurt: Fischer 1977, 5-6. 
de encontrar en otras latitudes. En cualquier caso, y sea como fuere, resulta evidente que los juicios emitidos en ambas novelas son demasiado tajantes y definitorios, demasiado globales y generalizadores como para poder afirmar que el autor se atiene al rigor histórico y es exacto y minucioso en sus descripciones y afirmaciones. Y esto es así, seguramente porque, por un lado, Feuchtwanger toma el ideal caballeresco en una acepción muy genérica, sin tener en cuenta que este ideal fue evolucionando y que, además, este ideal guerrero no es exclusivamente hispano, sino que también otros pueblos son conocidos en la Historia por su instinto belicoso; por otro, porque disocia en todo momento el poder del pueblo, definiendo las relaciones de poder tan sólo entre la Iglesia y el rey, sin tener en cuenta que tanto monarcas como prelados no eran sino parte del pueblo, y que además el propio pueblo, más si se quiere que las clases dirigentes, estaba empeñado en la tarea de la expulsión de los musulmanes y, por ende, de la unidad nacional.

Esta relación idílica entre Iglesia y Estado ha estado en realidad llena de grandes paradojas a lo largo de toda la Historia de España y, en verdad, fueron muy pocos los periodos en los que el diálogo entre Roma y la monarquía española no se vio sometido a fuertes tensiones. La nación española se distinguía ya desde antiguo por un marcado anticlericalismo que no interesó hacer ver hacia fuera: la religión católica era una creencia que no excluía la crítica feroz contra aquellos representantes de la Iglesia que tenían un comportamiento corrupto y esto fue así hasta el extremo de que, en tiempos de Felipe II, los ataques a la Iglesia y las censuras al clero comenzaron a ser considerados como herejías ${ }^{18}$. La Inquisición luchó con-

18 La literatura española se hizo eco de este anticlericalismo desde muy temprano. Así, por ejemplo, en el Libro de Buen Amor pueden leerse pasajes como el siguiente: "Yo vi a muchos monges en sus predicaçiones / denostar al dinero e a sus tenptaçiones; / en cabo, por dyneros otorgan los perdones, / asuelven los ayunos e fazen oraçiones. // Peroque lo denuestan los monges por las plaças, / guárdanlo en convento en vasos e en taças: / con el dinero cunplen sus menguas e sus raças: / más condedijos tiene que tordos nin picaças. // Monges, clérigos e frayres, que aman a Dios servir, / sy varruntan que el rrico está para moryr, / quando oyen sus dineros, que comyençan rreteñir, / quál dellos lo levará, comyençan a reñir." Arcipreste de Hita, Libro de Buen Amor. Madrid: EspasaCalpe ${ }^{14} 1976$, 56. O también en el Lazarillo, cuyo autor anónimo arremete 
tra el anticlericalismo, que se asentaba sobre todo en los hombres de letras y en las grandes cabezas del reino, y así la religión llegó a convertirse en una postura política, en una ideología, a favor o en contra de la cual se combatía. Precisamente en el siglo XIX tuvo lugar la conocida desamortización que Juan Alvárez de Mendizábal llevó a cabo de todos los bienes propiedad de la iglesia. El mito ${ }^{19}$ que Feuchtwanger construye como telón de fondo de sus novelas de esa España católica, religiosa y guerrera, de ese pueblo de teólogos y soldados, se convirtió, es cierto, en una cuestión política en diferentes momentos de crisis, en los que se temió por la pérdida de la España católica y, con ella, del poder conservador, pero la realidad que se vivía en el seno de la península era otra muy distinta.

Feuchtwanger, decidido a escribir sobre la figura de Goya, a quien veía como el fundador de la pintura moderna, desde su viaje a España en 1926, trata de convertir al pintor aragonés en protagonista de su novela para demostrar cómo se refleja el proceso de compromiso social en la figura de un artista que, nacido en el seno de una humilde familia ${ }^{20}$, ha sabido llegar hasta lo más alto en su profesión. No obstante, y a pesar de que el hilo conductor, está llevado en todo momento por la figura del protagonista que da título a la novela, lo que se lee detrás de ese periodo de la biografía de Goya es un cuadro interesantísimo de la España de la época, gobernada

burlonamente contra el estamento religioso: "Otro día, no pareciéndome estar allí seguro, fuíme a un lugar que llaman Maqueda, adonde me toparon mis pecados con un clérigo, que, llegando a pedir limosna, me preguntó si sabía ayudar a misa. Yo dije que sí, como era verdad. Que, aunque maltratado, mil cosas buenas me mostró el pecador del ciego, y una dellas fué ésta. Finalmente, el clérigo me reicbió por suyo. / Escapé del trueno y di en el relámpago. Porque era el ciego para con éste un Alejandro Magno, con ser la misma avaricia, como he contado. No digo más sino que toda la laceria del mundo estaba encerrada en éste. No sé si de su cosecha era o lo había anexado con el hábito de la clerecía." Anónimo, Lazarillo de Tormes. Madrid: Espasa-Cslpe 1966, ${ }^{15} 63$.

19 Entiendo "mito" en el sentido de leyenda o narración que distorsiona el pasado o entorpece su conocimiento, tal como lo define la RAE.

20 Es éste otro de los "errores" en los que cae el autor al presentar a Goya como hijo de una familia humilde, cuando en realidad nació en el seno de una familia de hidalgos nobles venidos a menos. 
en la teoría por la persona del borbón Carlos IV, y en la práctica por la reina María Luisa y Manuel Godoy, amante de ésta y valido del rey. La pintura que Feuchtwanger hace de la Historia española de esa época bien puede parecer un fresco de Goya. Su enfoque, centrado de nuevo sobre aquellos mismos elementos que le sirvieran para configurar el retablo de la España medieval, la monarquía y el clero, o lo que es lo mismo, las clases dirigentes, el poder, no difiere en mucho del panóptico que dibuja en Die Jüdin von Toledo, pues aquí también las cuestiones políticas y las relaciones que se establecen en torno al poder pesan más que la cultura prácticamente prohibida y anulada por la sacrosanta Inquisición, la cual tachaba de herejía todo aquello que no comulgara con sus estrictos preceptos. De ahí que el desinterés cultural del pueblo español no tenga sus raíces en la dejadez o en la falta de interés, sino más bien en el miedo y en su disposición a acatar los preceptos impuestos desde las altas esferas del poder. Feuchtwanger divide la novela en tres partes que recogen los acontecimientos acaecidos entre los años 1793 y 1803, cada una de las cuales ayuda a conformar esa pintura generalizada con sumo detalle: el primero con una introducción de carácter histórico-político, el segundo con un repaso a la historia de la Inquisición, y el tercero con la descripción de la fuerza y el empuje con el que llegan las nuevas ideas revolucionarias, que ni siquiera el bonapartismo fue capaz de erradicar.

Centro de todos ellos es la persona de Goya, a través del cual el autor se permite la osadía de introducirse en los más diversos ambientes - desde las camas de palacio hasta los barrios de los arrabales llenos de inmundiciay ello simple y llanamente porque el pintor pertenece a esos dos mundos: al mundo del pueblo, de los majos, por su humilde nacimiento, y al de la realeza y los nobles, por su condición de pintor de cámara. La elección del personaje resulta, por tanto, oportuna más que por lo que pueda aportar a la evolución de la pintura, por la información que el lector obtiene a través de la descripción de los ambientes en los que se mueve y las gentes con las que conversa. Al final de la obra, el pintor protagonista habrá recorrido el mismo camino que la España de la época, pues se habrá librado de las férreas cadenas del clasicismo dominante, será consciente de cuál es su posición en la sociedad y habrá elaborado una concepción política propia, la del liberalismo, acorde con las ideas del momento. En claro paralelismo, 
la España de principios del siglo XIX tratará de librarse de las férreas cadenas bonapartistas, tratará de encontrar de nuevo su situación en el curso de la Historia y, en ella, el liberalismo irá echando raíces hasta desembocar, un siglo después, en el triunfo de la República como forma de gobierno. De nuevo una repetición de la Historia, un caso de poder mal ejercido que trae consigo también unas consecuencias tan negativas como las que se veían en la primera novela.

Pero, al igual que ocurría con la figura de Alfonso VIII en la novela anterior, en ésta tampoco Feuchtwanger se ajusta a la verdad histórica, si bien es cierto que el uso de determinados términos, el conocimiento de determinadas anécdotas y las descripciones de los tipos populares hacen ver que el autor se había documentado suficientemente sobre España. Y precisamente en el hecho de esa minuciosa documentación es donde se plantea el problema de por qué sus descripciones resultan a veces tan estereotipadas, como si fueran producto más bien de lecturas foráneas que del conocimiento del país in situ. Son demasiados los clichés que aparecen en el texto, ya sea acerca de la Inquisición ${ }^{21}$ o de cualquier otro elemento singular de la vida española, los cuales contribuyen a configurar negativamente una imagen que resulta para Feuchtwanger en síntesis de la Historia de una nación, que él ha querido presentar valiéndose de la técnica literaria que domina toda su producción histórica: la del contraste. La recreación literaria del belicoso Alfonso VIII, el rey que inició las campañas contra los almohades el mismo día que cumplió la mayoría de edad, no puede tener mejor contraste que la figura del anodino Carlos IV, más preocupado de sus relojes que del gobierno, el cual dejó la política en manos de su esposa María Luisa de Parma, mujer de talante intrigante y manifiesta falta de discreción. Fue ella quien dominó siempre a su indolente esposo, logrando

21 Las páginas que dedica a la Inquisición en la novela sobre Goya resultan, a mi modo de ver, excesivas por lo que al contexto de la novela en general se refiere. Pero entiendo que al lector alemán de seguro le resultaba enormemente interesante la descripción minuciosa de estos procesos de persecución contra todo aquel que tenía o era sospechoso de tener ideas diferentes a las permitidas por la Iglesia católica, algo extrapolable a la situación vivida por buena parte del pueblo alemán durante el periodo del nacionalsocialismo y la guerra. 
mantenerlo apartado de la vida política mientras ella participaba en todas las intrigas cortesanas y asumía los asuntos de Estado. La ambición de esta reina, no obstante, fue mayor que su capacidad, por lo que muy pronto delegó las tareas de gobierno en su amante Manuel Godoy, y utilizó toda su influencia para hacer de él el hombre más poderoso de la corte. Es, pues, en este punto, evidentemente el núcleo de ambas obras, donde Feuchtwanger acierta de pleno en la elección de sus personajes sacados de la Historia de España. Otra cosa muy distinta es la descripción del país en las diferentes épocas en que se centran las obras, así como la imagen desproporcionada, hasta el ridículo en ocasiones, de los españoles del momento. La plata de las colonias americanas, que llega cada vez en menor cantidad, la Revolución Francesa y Napoleón, el mal gobierno que arruina la nación, el contrabando y el bandolerismo son fenómenos que adquieren aquí una dimensión exagerada $^{22}$. Cierto es que las clases dirigentes no se percatan de los peligros de la situación y más bien se desinteresan de ella, pues la vida cómoda y confortable en palacio menoscaba su sentido de la responsabilidad. El pueblo vive al día, confortado con el pan y las corridas de toros. Es una visión fatalista de un pueblo que, con muy pocos motivos, vive con júbilo y alegría, en una fiesta perenne, guiado seguramente por el dicho de que quien se contenta con lo que tiene, disfruta.

Como justificación, en último término, de tal percepción, no debe olvidarse que la novela histórica no pretende falsear o manipular la Historia. Es decir que, por lo general, el autor adolece de la concreción necesaria a la hora de describir los acontecimientos históricos, y tampoco lleva a cabo un uso adecuado de las fuentes, alterando todo aquello que considera necesario

22 Que Feuchtwanger, en ese ánimo de conferir un carácter bélico a todo lo que hace el pueblo español llega a extremos exagerados, se refleja por ejemplo en esta descripción que hace del sencillo baile de la jota aragonesa: “[...] er selber aber in seinem Innern tanzte seine eingeborene aragonesische Jota, diesen geradezu kriegerischen Tanz, in welchem Mann und Weib einander bedrohen, einen Tanz ohne Anmut und ohne Schonung, voll gehaltener Leidenschaft, er hatte ihn oft getanzt, sehr aufrecht, wie es der Tanz verlangte, als ginge man in eine Schlacht. Und mit den andern im Takt klatschte er in seine kräftigen Hände und schrie mit hoher Stimme Olé”. FeuchTWANGER, Lion, Goya oder Der arge Weg der Erkenntnis. Frankfurt: Fischer 1977, 384. 
para llevar a cabo la construcción de su trama novelesca. Pero no se puede olvidar que la novela histórica es, ante todo, una obra literaria, nunca historiográfica, y su finalidad no es otra que la de simbolizar no la realidad de los datos históricos, sino la que se oculta tras ellos, o lo que es lo mismo, la novela histórica es ficción, no realidad.

$\mathrm{El}$ análisis de estas dos novelas, pues, nos da como resultado un punto de vista común: sobre el fondo de unos paisajes difuminados, que no ocupan lugar en los textos más que como paisajes desdibujados, propios de un escenario bélico, se despliega un espíritu guerrero ambicioso y desmesurado, amparado siempre en una ciega fe en Dios y en una idea de gobierno encarnada en la sagrada persona del monarca absoluto. Esta imagen como síntesis de siete siglos de la Historia española resulta un tanto pobre, pero se adapta perfectamente a la expresión a través del pasado de un momento de similares características vivido por los propios autores: el nacionalsocialismo y la consiguiente guerra mundial. Lo que proyectan sobre su visión de España no es otra cosa que su propia experiencia de la Alemania de los años treinta y de los que siguieron hasta el final del conflicto bélico. Que en esta proyección se altera la visión de la Historia de España resulta evidente, pero ¿por qué precisamente la de España y no la de cualquier otro país? Seguramente porque, a pesar de la visión negativa, el ideal perseguido y mantenido por el pueblo español, su perseverancia a lo largo de los siglos, su particular idiosincrasia y su actitud ante los avatares de la Historia, han resultado siempre enormemente atractivos para los escritores alemanes que, incapaces de comprenderlo en muchos casos, tan sólo han sabido criticarlo.

\section{Referencias bibliográficas}

Aust, Hugo. Der historische Roman. Stuttgart, Metzler 1994.

DietsChreit, Frank. Lion Feuchtwanger. Stuttgart, Metzler 1988.

Esteve Montenegro, María-Luisa. La imagen de España en la literatura alemana del exilio de 1933-1945. Frankfurt, Peter Lang 1988.

García de Cortázar, Fernando. Los mitos de la Historia de España. Barcelona, Plantea 2005. 
Hernández, Isabel. „Lion Feuchtwanger: Die Jüdin von Toledo. Un tema español en la literatura alemana”. In: Raders, Margit / Schilling, $\mathrm{M}^{\mathrm{a}}$ Luisa (eds.). Deutsch-spanische Literatur- und Kulturbeziehungen - Relaciones hispanoalemanas en la literatura y en la cultura. Madrid, Del Orto 1995, 237-246.

Hernández, Isabel. "Visiones de la Historia desde el exilio: Lion Feuchtwanger y su reconstrucción de la leyenda de la Judía de Toledo". In: Estudios de Filología Moderna 4 / 2004, 133-148.

Hernández, Isabel. „Mauern, Türme, Schlösser und Gärten. Gestalt und Bedeutung maurischer Landschaften in Lion Feuchtwangers Roman Die Jüdin von Toledo". In: Ecker, Hans-Peter (ed.). Gärten - Spiegel der Seele. Würzburg, Ergon (en prensa).

KoHPEIss, Ralph. Der historische Roman der Gegenwart in der Bundesrepublik Deutschland. Ästhetische Konzeption und Wirkungsintention. Frankfurt, Verlag für Wissenschaft und Forschung 1993.

Menéndez Pidal, Ramón. Los españoles en la historia. Espasa-Calpe: Madrid 1982 (1947).

MenÉndez Pidal, Ramón. Los españoles en la literatura. Madrid, Espasa-Calpe 1971 (1949).

vON Sternburg, Wilhelm (ed.). Lion Feuchtwanger. Materialien zu Leben und Werk. Frankfurt, Fischer 1989. 